\title{
LA ETERNIDAD DEL MUNDO ENTRE EDAD MEDIA Y RENACIMIENTO
}

Los artículos que se publican a continuación bajo el título general de «La eternidad del mundo entre Edad Media y Renacimiento» tienen su origen en las ponencias que se leyeron en la Jornada Eternidad del mundo y memoria entre Edad Media y Renacimiento, celebrada en la Universidad de Barcelona el 5 de mayo de 2012. Aparecen ahora tras haber sido sometidos por sus autores a una profunda revisión. El título de la jornada hacía referencia al famoso pasaje de los Discorsi de Maquiavelo (libro II, capítulo 5) donde, según el secretario florentino, se podía responder a la dificultad que para la tesis de la eternidad del mundo y de la especie humana (tesis fundamentalmente aristotélica) representaba la limitación de la memoria humana a no más de cinco mil años (la antigüedad del mundo según la cronología bíblica) remitiendo al hecho, ampliamente constatado, de la desaparición de la memoria colectiva humana por causas naturales (catástrofes de agua y fuego) y humanas (cambios de religión y de lenguas).

La vinculación del problema de la memoria histórica con la tesis de la eternidad del mundo no se ha constatado en todos los autores estudiados en los artículos que siguen. Es el caso de Maimónides y Pietro Pomponazzi. Maquiavelo presenta el problema en el capítulo anteriormente mencionado, en una exposición que ha generado una extensa discusión historiográfica. La eternidad del mundo, o mejor del universo, es también tema de discusión en Montaigne, con una ostensible propensión hacia la «inmensidad» temporal, y es objeto de afirmación rotunda por parte de Giordano Bruno. La ponencia sobre Averroes y el averroísmo no ha sido finalmente consignada para publicación por su autor.

La jornada que ha dado lugar a estos artículos se celebró en conexión con el proyecto de investigación FFI2009-07156 «Cosmología, teología y antropología en la primera fase de la Revolución Científica (1543-1633)», financiado por el Gobierno Español (Ministerio de Ciencia e Innovación).

Miguel Á. Granada 